\title{
Symposium review: Animal welfare in free-walk systems in Europe*
}

\author{
Isabel Blanco-Penedo, ${ }^{1} \dagger$ Wijbrand Ouweltjes, ${ }^{2}$ Elfriede Ofner-Schröck, ${ }^{3}$ Kerstin Brügemann, ${ }^{4}$ \\ and UIf Emanuelson ${ }^{1}$ \\ ${ }^{1}$ Swedish University of Agricultural Sciences, Department of Clinical Sciences, SE-75007 Uppsala, Sweden \\ ${ }^{2}$ Wageningen UR Livestock Research, 8200 AB, Lelystad, the Netherlands \\ ${ }^{3}$ HBLFA Raumberg-Gumpenstein, 8952 Irdning-Donnersbachtal, Austria \\ ${ }^{4}$ Institute of Animal Breeding and Genetics, Justus-Liebig-University, D-35390 Giessen, Germany
}

\begin{abstract}
Providing more space per animal, soft bedding, and free roaming in animal housing systems is widely presumed to be beneficial for the welfare of the animals. This observational study aimed to investigate the basis of this assumption in free-walk housing systems (FWS) for dairy cows in Europe. The dairy cattle Welfare Quality assessment protocol was adapted for application to FWS, and the focus was on animal-based measures, from individual cow scoring to comfort around resting. The study was conducted on 41 farms [21 FWS and 20 cubicle housing $(\mathrm{CH})$ ] from 6 European countries (Germany, the Netherlands, Italy, Austria, Slovenia, and Sweden) displaying a variety of management systems. A total of 4,036 animals were scored. We found differences in animal welfare under different management conditions. The hindquarters and lower hind legs of cows from FWS were dirtier than those of cows in $\mathrm{CH}$, but we found no difference in the dirtiness of udders or teats. Cows from FWS showed fewer hairless patches in all body areas except the neck; fewer lesions in the lower hind legs and hindquarters; and less swelling in the lower hind legs, flanks, and carpus than cows from $\mathrm{CH}$. The prevalence of sound cows appeared to be higher in FWS, and moderate lameness prevalence was lower compared with $\mathrm{CH}$. We found no difference in the prevalence of severe lameness between systems. We conducted a total of 684 observation sessions of comfort around resting, consisting of 830 lying down and 849 rising up movements. Cows in FWS took less time to lie down, had less difficulty rising up, and had fewer collisions with the environment during both behaviors than cows in $\mathrm{CH}$. Cows lay partly or completely outside the supposed lying area less frequently in FWS than
\end{abstract}

Received July 23, 2019.

Accepted December 23, 2019.

*Presented as part of the Production, Management, and Environment Symposium: Future of Housing for Dairy Cattle at the ADSA Annual Meeting, Cincinnati, Ohio, June 2019.

†Corresponding author: isabel.blanco.penedo@slu.se in $\mathrm{CH}$. Cows in FWS adopted comfortable lying positions more often compared with $\mathrm{CH}$, showing a higher occurrence of long and wide positions than cows in $\mathrm{CH}$. Short positions were more common in FWS, and narrow positions were slightly more common in $\mathrm{CH}$. We found large variations in animal-based measures between study herds and within housing systems. However, the observed patterns associated with each system demonstrated differences in cow scoring and comfort around resting. This study shows that a wide range of good and bad management practices exist in FWS, especially related to cow hygiene.

Key words: dairy cow, alternative housing, welfare, compost-bedded pack

\section{INTRODUCTION}

In the last 50 years, the main goal of dairy farming has been to increase milk production through genetic selection and improved management, thereby increasing farm profit and reducing costs for consumers (Krug et al., 2015). However, concerns related to animal care and handling have grown among European citizens, making the welfare status of farm animals an important aspect of overall food quality (Eurobarometer, 2016) and of the sustainability of animal production (Hötzel, 2014).

Farming systems are important factors that affect animal health and welfare, partly through housing and equipment and partly through management and handling practices (EFSA, 2012). Although the body of legislation on animal welfare in the European Union has grown, only a few member states have specific legislation related to housing for adult dairy cattle (e.g., Denmark, Austria, Sweden; European Union, 2017). There is considerable diversity in how cows are housed and where lactating dairy cows spend the majority of their time. For example, tie-stall housing systems are still used extensively in Europe, despite growing criticism that they restrict opportunities for voluntary movement and social behavior (EFSA, 2009). However, 
differences between climatic regions and the management of housing systems are the greatest source of heterogeneity in the living conditions offered to cattle in Europe.

Freedom from pain and injuries and the ability to perform natural behaviors are important requirements in securing animal welfare on farm (Brambell Committee, 1965). Assuring a certain level of welfare for dairy cattle requires the assessment of welfare on a regular basis and, if needed, improvement of housing and management practices. Skin lesions or alterations are commonly observed in some housing systems (e.g., Veissier et al., 2004; Kielland et al., 2009; Brenninkmeyer et al., 2016). They reflect an impairment of cows' welfare, because wounds and swellings may be painful in themselves, and alterations such as hairless areas reflect repeated conflicts between the cow and its environment. Lameness continues to be the main welfare issue in dairy cows, affecting their physical fitness and mental state (suffering); lameness is also one of the main causes of economic loss (e.g., yield, fertility, culling; EFSA, 2009; Grandin, 2018) and is clearly related to housing conditions (Webster, 2001; Somers et al., 2003; Rutherford et al., 2009). Housing also has a substantial effect on comfort around resting. Lack of lying comfort has an effect on the production and welfare of dairy cows (Munksgaard et al., 2005). The effects of barn design on standing and lying behavior have been the focus of considerable research in recent years, especially in how to maximize cow comfort. This work shows that cows prefer lying surfaces with more bedding (Tucker and Weary, 2001), they lie more per day in well-bedded stalls versus those that are not (Tucker et al., 2009), and they prefer dry (Fregonesi et al., 2009) and well-maintained (Drissler et al., 2005) bedding.

Innovative free-walk housing systems (FWS) - that is, the "bedded pack barn" or "compost/composting barn" and "artificial floor barn" - are promising housing systems for promoting animal well-being. In these alternative housing systems, cows are given a large area for resting instead of individual stalls. The FWS has the flexibility to meet the space, exercise, resting, and social needs of cows (Galama, 2011), but it has not yet been fully scientifically tested and is still in its infancy.

Experiences with compost-bedded pack barns for dairy cows in the United States have been reported in the literature (Endres and Barberg, 2007). However, despite the increased popularity of FWS in Central Europe, its characterization in Europe for the dairy sector and from dairy research is still lacking, except for a few national examples from the Netherlands (Galama, 2011), Austria (Ofner-Schröck et al., 2015), and Italy
(Leso et al., 2013). Very little of the literature specifically addresses the welfare risks of FWS (Ofner-Schröck et al., 2015), and no studies examine welfare under different geographical conditions in Europe. The aim of this observational study was to evaluate the welfare of 2 housing systems in the most comprehensive way to date in 6 European countries and to identify major challenges and caveats.

\section{MATERIALS AND METHODS}

\section{Study Herds}

The present study is part of a larger project to investigate animal health and welfare, milk quality, and environmental and socioeconomic impacts in dairy farms that use FWS versus cubicle housing $(\mathbf{C H})$ systems (ERA-Net Cofund SusAn; grant no 696231).

The selection of farms was based on overall project requirements. Farms were selected based on certain inclusion criteria to ensure that the sample was representative of dairy production in the respective countries (i.e., a herd size and milk production level typical of the country) and used the housing system for their lactating herd for at least 6 mo before the first farm visit (to exclude "conversion" effects and have a more or less stable situation). In Sweden and Slovenia, all farms using FWS were recruited for the study. Twenty-one commercial dairy farms with FWS in 6 European countries (6 in Germany, 6 in the Netherlands, 4 in Italy, 3 in Austria, 1 in Slovenia, 1 in Sweden) were recruited for cattle welfare evaluation. It was decided that the survey should be conducted in these 6 countries, because the sample would cover the broadest diversity of FWS. Matching reference farms with $\mathrm{CH}$ were recruited and required to have herd size, production level, breed, and location similar to those of the case farms with FWS.

Farms were visited during the winter of 2017 to 2018, when the cows were housed, and during summer 2018, when some of the farms provided grazing for the cows. One farm from the Netherlands was visited only in summer. For all study visits, no routine claw trimming sessions occurred in the 4 weeks preceding the visit (if applicable).

Dry cows were not included in the evaluation if they were kept in other barns or on pasture all year. Four farms used both FWS and CH housing, depending on the cows' stage of lactation; those farms were integrated into the FWS group for practical reasons.

General herd characteristics were obtained from questionnaires and DHIA records. General information about the farms and animals included in the study are reported in Tables 1 and 2 . 
Table 1. Characteristics of 21 dairy herds with free-walk housing systems (FWS) and 20 dairy herds with cubicle housing systems $(\mathrm{CH})$ obtained from questionnaires

\begin{tabular}{|c|c|c|}
\hline Variable & FWS & $\mathrm{CH}$ \\
\hline Average number of cows (range) & $117.0(16-720)$ & $115.6(30-270)$ \\
\hline Total area, ha & 96.0 & 103.3 \\
\hline Herds with grazing, no. & 10 & 8 \\
\hline Average grazing, d/yr (range) & $98.0(0-300)$ & $85.4(0-300)$ \\
\hline Average grazing, $\mathrm{h} / \mathrm{d}$ (range) & $6.8(0-24)$ & $6.6(0-24)$ \\
\hline \multicolumn{3}{|l|}{ Predominant breed, $\%$} \\
\hline Holstein-Friesian & 66 & 70 \\
\hline Non-Holstein-Friesian & 33 & 30 \\
\hline \multicolumn{3}{|l|}{ Milking system, \% } \\
\hline Parlor & 66 & 60 \\
\hline Automatic milking system & 33 & 40 \\
\hline Herds with routine herd claw trimming, ${ }^{1} \%$ & 73.3 & 76.4 \\
\hline Herds planning 1 trimming/yr, ${ }^{1} \%$ & 75 & 76.4 \\
\hline Herds planning 2 trimmings $/ \mathrm{yr}^{1}, \%$ & 25 & 23.5 \\
\hline $\begin{array}{l}\text { Individual cow claw trimming between herd } \\
\text { trimming events, }{ }^{1} \%\end{array}$ & Yes (93) & Yes (94) \\
\hline
\end{tabular}

${ }^{1}$ Information was missing for 4 farms.

\section{On-Farm Welfare Assessment and Data Collection}

The European Welfare Quality (WQ) project developed protocols for dairy cattle and other domestic species that resulted in on-farm monitoring systems (Welfare Quality, 2009). All data were collected by the same observer (IBP), who received the required training to implement the WQ protocol.

The WQ protocol for dairy cattle consists of 30 measures that cover 4 principles: health, feeding, housing, and behavior. The protocol was revised by a focus group consisting of the authors of this study to adapt it to the conditions of FWS (adding measures and new considerations for field implementation). The same risk factors and welfare consequences, as measured by corresponding animal-based measures (ABM) already identified for intensive farming systems, were considered to be relevant for FWS.

The focus for ABM in the current study was individual cow scoring, such as hygiene, skin lesions or alterations, and locomotion, and ABM on comfort around resting (for more details, see Supplemental Table S1; https://doi.org/10.3168/jds.2019-17315). For the lat- ter, cows were monitored for the time needed for lying down, collision with equipment, and the percentage of animals lying outside the lying area. All aspects were recorded following the instructions of the WQ protocol. The hygiene score of the lower hind legs, hindquarters, and udders was assessed using scores 0 (clean), 1 (minor splashing), or 2 (dirty). The proportion of cows awarded a score of 2 for each of the measures was calculated separately for each farm. Skin lesions or alterations were recorded as present or absent, and the number of injuries per body area was also recorded. The farm prevalence of cows with skin lesions or alterations was also calculated.

In addition, new $\mathrm{ABM}$ considered specifically relevant for FWS were added: (1) hygiene of teats, (2) ease of rising up movement, (3) collision with the environment (equipment and other animals) when standing up, (4) overgrown claws, and (5) resting positions. Resourcebased measures (related to the physical environment and resources available to an animal) and management practices were added, because they were needed to respond to the research questions and were likely to be present in FWS.

Table 2. Characteristics (median, 1st and 3rd quartile) of cows in 21 dairy herds with free-walk housing systems (FWS) and 20 dairy herds with cubicle housing systems $(\mathrm{CH})$ obtained from DHIA records

\begin{tabular}{lcc}
\hline Variable & FWS & CH \\
\hline Test-day milk yield, kg & $30.2(23.6-36.9)$ & $31.9(25.8-38.8)$ \\
Test-day milk fat, $\%$ & $4.01(3.53-4.53)$ & $4.09(3.64-4.58)$ \\
Test-day milk protein, $\%$ & $3.50(3.25-3.77)$ & $3.49(3.23-3.76)$ \\
Lactation yield, kg of milk & $9,566(7,698-11,193)$ & $10,174(8,470-11,762)$ \\
SCC, 1,000 cells/mL & $79(34-207)$ & $64(28-163)$ \\
Age at first calving, mo & $25.3(23.8-27.8)$ & $24.9(23.8-26.9)$ \\
Average calving number & $2(1-4)$ & $2(1-3)$ \\
Calving interval, d & $378(351-424)$ & $386(357-440)$ \\
\hline
\end{tabular}


In contrast to the WQ protocol, teats were scored separately from the udder in the present study, and teats were also scored 0 (clean), 1 (minor splashing), or 2 (dirty). Rising up movement was evaluated following the method of Tillie (1986), assigning a score of 1 to 5 depending on how smooth or fluid the movement was, whether there was a pause on the carpal joints, and whether it followed a normal sequence of events (intraobserver validity was not performed for this measurement). Overgrown claws were evaluated as indicated in the WQ reports (Leach and Whay, 2009) and in Toussaint-Raven (2003), considering consistent contact of the claws with the surface, the angle and length of the claws, and the space between them. Finally, resting positions were registered as described by Anderson (2008), considering the body and head position (head back, head up, body flat on the side, and head on the ground).

Farm visits started in the morning, when cows were still at milking, for farms with conventional milking systems as suggested by the WQ assessment protocol for dairy cattle and before the morning feeding on farms with automatic milking systems (a time when most cows start their daily activities). On every farm around the time of first milking ( $0500 \mathrm{~h}$ to $0700 \mathrm{~h})$, the complete WQ audit was performed. The full execution of the protocol took 7 to $11 \mathrm{~h}$ per farm visit. Resourcebased measures at the farm were examined at the end of the on-farm welfare assessment.

Following the sample size recommendation from the WQ protocol (i.e., less than 30 animals in the herd, all animals sampled; more than 30 animals, samples according to specific sample size calculations), 17 to 98 cows were randomly selected using the systematic random selection approach recommended in the WQ protocol and assessed at each farm. Briefly, if animals could be fixed in a feeding rack, they could be selected by choosing every nth animal in the rows. Otherwise, animals in all areas of the barn were considered, including those standing, eating, and lying. Primiparous and multiparous cows were included in the study, as well as dry cows - the latter only if they were housed in the same barn as the milking cows. Each cow was assessed using the clinical indicators from the adapted version of the WQ protocol. In total, 4,036 dairy cows were assessed.

During data collection, all lactating cows were in the barn. Cows were inspected while they were held in headlocks or standing in the feeding alley. Lameness was assessed while cows were standing and when they were moving, as described in the WQ protocol. The scoring system focuses on evaluating the timing of steps, weight bearing, temporal rhythm, and reluctance to move. A headlight was used for visual inspection, if necessary. For the other behavioral observations, cows were observed in groups (average 14 cows, ranging from 7 to 32 ) for $2 \mathrm{~h}$ in the barn as instructed by the WQ protocol (Welfare Quality, 2009).

The majority of the ABM and resource-based measures were recorded by direct observation of the cows and their environment at the farm level. A few parameters regarding resources and management of the farm were provided by the farmer through a questionnaire during the first visit. When available, DHIA records were also examined to obtain general information about the herds.

\section{Statistical Analysis}

Data analysis in this study was for descriptive purposes only. Two different measures were calculated: mean numbers of alterations at the cow level, and prevalence at the herd level (with farm as the experimental unit). The correlation of different welfare measures was described using the Spearman rank correlation coefficient. Only significant correlations with an $\mathrm{r}$ value $>0.2$ are reported. At the herd level, coefficients of intrafarm variation (as a measure of the dispersion of data points in each farm data series around the mean) were calculated. All analyses were performed using STATA (Stata Corp., College Station, TX).

\section{RESULTS}

\section{Cow Scoring: Hygiene, Skin Lesions or Alterations, Locomotion Score}

We found differences between the 2 housing systems for the majority of the ABM, indicating positive and negative effects in both systems. The main results from the cow scoring are presented in Tables 3,4 , and 5 .

The overall average dirtiness (composite of hygiene scores 1 and 2) for all cows assessed was 0.95 for the

Table 3. Farm prevalence of animal-based measures related to hygiene and locomotion in 21 dairy herds with free-walk housing systems (FWS) and 20 dairy herds with cubicle housing systems $(\mathrm{CH})^{1}$

\begin{tabular}{lcc}
\hline Measures, \% & FWS & $\mathrm{CH}$ \\
\hline Hygiene & 70.5 & 55.7 \\
Dirty lower hind legs & 51.5 & 36.1 \\
Dirty hindquarters & 37.6 & 34.9 \\
Dirty udder & 13.4 & 11.8 \\
Dirty teats & & \\
Locomotion & 77.6 & 71.6 \\
Sound & 17.5 & 21.2 \\
Moderately lame & 4.96 & 6.21 \\
Severely lame & 11.7 & 12.2 \\
Overgrown claws &
\end{tabular}

${ }^{1} \mathrm{n}=4,036 ; 2,067$ in FWS and 1,969 in CH. 
Table 4. Farm prevalence of animal-based measures related to integument alterations in 21 dairy herds with free-walk housing systems (FWS) and 20 dairy herds with cubicle housing systems $(\mathrm{CH})^{2}$

\begin{tabular}{lll}
\hline Measures, \% & FWS & CH \\
\hline Hairless patches & 0.78 & \\
Lower hind legs & 0.79 & 2.14 \\
Hindquarters & 0.41 & 1.75 \\
Neck-shoulder-back & 0.41 & 0.34 \\
Flank side udder & 0.47 & 0.34 \\
Carpus & & 1.01 \\
Lesions & 0.32 & 0.17 \\
Lower hind legs & 0.12 & 0.09 \\
Hindquarters & 0.01 & 0.03 \\
Neck-shoulder-back & 0.009 & 0.003 \\
Flank side udder & 0.002 & 0.004 \\
Carpus & & \\
Swelling & 2.22 & 4.31 \\
Lower hind legs & 0.13 & 0.22 \\
Hindquarters & 0.1 & 0.3 \\
Neck-shoulder-back & 0.13 & 0.21 \\
Flank side udder & 3.92 & 1.57 \\
Carpus & & \\
\hline
\end{tabular}

${ }^{1} \mathrm{n}=4,036 ; 2,067$ in FWS and 1,969 in $\mathrm{CH}$.

hind legs, 0.90 for the hindquarter, 0.74 for the udder, and 0.41 for the teats. The proportions of "very dirty" (hygiene score of 2) were 35.1 and $27.1 \%$ for the lower hind legs, 25.6 and $17.3 \%$ for the hindquarters, 18.5 and $16.6 \%$ for the udders, and 6.1 and $5.3 \%$ for the teats in FWS and CH, respectively. The animals were generally dirtier in summer and if grazing was provided (data not shown). Dirty hindquarters and lower hind legs were more common in FWS than in $\mathrm{CH}$, but we found no differences in udder or teat dirtiness. The coefficients of variation for farm prevalence of "very dirty" were 27.7 and $55.4 \%$ for lower hind legs, 32.4 and $54.9 \%$ for hindquarters, 37.5 and $56.9 \%$ for udders, and 80.3 and $101.6 \%$ for teats in FWS and CH, respectively.

We observed stronger Spearman correlations $\left(\mathbf{r}_{\mathbf{s}}\right)$ in $\mathrm{CH}$ than in FWS at the herd level among the percentage of cows with dirty body regions (CH vs. FWS; udder and lower hind legs, $\mathrm{r}_{\mathrm{s}}=0.84$ vs. $0.73, P<0.001$; udder and hindquarters, $\mathrm{r}_{\mathrm{s}}=0.89$ vs. 0.79 ; dirty teats

Table 5. Farm prevalence of animal-based measures related to health parameters in 21 dairy herds with free-walk housing systems (FWS) and 20 dairy herds with cubicle housing systems $(\mathrm{CH})^{1}$

\begin{tabular}{lcc}
\hline Measures, \% & FWS & CH \\
\hline Nasal discharge & 1.52 & 1.69 \\
Ocular discharge & 5.62 & 2.08 \\
Purulent ocular discharge & 0.39 & 0.16 \\
Vulva discharge & 2.11 & 2.25 \\
Hampered respiration & 1.75 & 0.70 \\
Bloated rumen & 0.09 & 0 \\
Diarrhea & 1.08 & 0.72 \\
\hline
\end{tabular}

${ }^{1} \mathrm{n}=4,036 ; 2,067$ in FWS and 1,969 in CH. and lower hind legs, $\mathrm{r}_{\mathrm{s}}=0.56$ vs. $0.28, P<0.001$; and teats and hindquarters, $\mathrm{r}_{\mathrm{s}}=0.73$ vs. 0.42 ).

Regarding skin lesions or alterations in the defined body areas, hairless patches were most pronounced on lower hind legs and carpus. Lesions were more frequent in tarsus and hindquarters, and swelling in carpus and tarsus. More cases were observed in summer than in the winter season. Distribution of prevalence at herd level was similar to the distribution of skin lesions/ alterations per cow. The prevalence of cows with at least one hairless patch, one lesion, or one swelling in the body areas appeared to be higher in $\mathrm{CH}$ in both winter and summer. The coefficients of variation of farm prevalence were 116.9 and $54.8 \%$ for hairless patches on the lower hind legs, 89.7 and $55.3 \%$ for hairless patches in the carpus, 112 and $82.4 \%$ for lesion in the tarsus, 120 and $71.4 \%$ for the hindquarters, 137 and $155 \%$ for swelling in the carpus, and 90 and $103 \%$ for swelling in the tarsus for FWS and $\mathrm{CH}$, respectively.

On average, we observed a higher proportion of sound cows in FWS than in $\mathrm{CH}$ (78.3 vs. $73.4 \%)$. The prevalence of moderately lame cows differed between systems, with a lower prevalence in FWS than in $\mathrm{CH}$ (16.6 vs. $20.5 \%$ ). The prevalence of severe lameness did not differ among systems (5.0\% in FWS vs. $6.0 \%$ in $\mathrm{CH})$. The difference between systems for prevalence of moderate lameness was the same in both seasons (data not shown). In general, poor claw condition was not associated with herd routines of trimming or with grazing practices, but we did find seasonal differences. The prevalence of lameness and overgrown claws was not correlated with trimming practices at the herd level. However, having individual cow claw trimming events between herd trimming events was correlated with the prevalence of severe lameness $\left(\mathrm{r}_{\mathrm{s}}=0.39, P<0.05\right)$ and the prevalence of sound cows $\left(\mathrm{r}_{\mathrm{s}}=-0.36, P<0.05\right)$. The number of individual trimmings was highly related to requirements to take care of severely lame cows, but might also contribute to a generally better lameness status on the farm in the long term. We observed a correlation between hairless patches in the tarsus and moderate lameness only in FWS $\left(\mathrm{r}_{\mathrm{s}}=0.22, P<0.05\right)$. Lesions in the tarsus and hindquarters were correlated with moderate lameness $\left(\mathrm{r}_{\mathrm{s}}=0.31, P<0.001 ; \mathrm{r}_{\mathrm{s}}=\right.$ $0.36, P<0.05)$ in $\mathrm{CH}$ but not in FWS. We observed correlations for swellings and moderate lameness in the hindquarters, flank, and udder but not in the tarsus and carpus in $\mathrm{CH}$. We found stronger correlations between severe lameness and swelling in the hindquarters in FWS $\left(\mathrm{r}_{\mathrm{s}}=0.60 ; P<0.05\right)$ and with swelling in the carpus in $\mathrm{CH}\left(\mathrm{r}_{\mathrm{s}}=0.49 ; P<0.05\right)$.

Most measures assessed for the criteria absence of diseases and principle of good health (i.e., frequency of coughing and cows with nasal discharge, ocular dis- 
Table 6. Animal-based measures related to comfort around resting of cows in 21 dairy herds with free-walk housing systems (FWS) and 20 dairy herds with cubicle housing systems $(\mathrm{CH})^{1}$

\begin{tabular}{|c|c|c|}
\hline Measures & FWS & $\mathrm{CH}$ \\
\hline \multicolumn{3}{|l|}{ Lying down behavior $(\mathrm{n}=830)$} \\
\hline Mean duration $(\mathrm{Q} 1-\mathrm{Q} 3){ }^{2} \mathrm{~s}$ & $5.32(4.60-6.25)$ & $6.00(5.20-7.25)$ \\
\hline Collisions, $\%$ & 7.6 & 35.3 \\
\hline Lying outside lying area, $\%$ & 3.0 & 5.7 \\
\hline \multicolumn{3}{|l|}{ Rising behavior $(\mathrm{n}=849)$} \\
\hline Mean rising score $(\mathrm{Q} 1-\mathrm{Q} 3),{ }_{\mathrm{s}} \mathrm{s}$ & $2.32(2-3)$ & $2.91(2-3)$ \\
\hline Collisions, \% & 18.4 & 76.8 \\
\hline \multicolumn{3}{|l|}{ Resting positions $(\mathrm{n}=4,127)$} \\
\hline Long position, $\%$ & 23.1 & 14.5 \\
\hline Wide position, \% & 27.8 & 12.9 \\
\hline Short position, $\%$ & 41.1 & 35.8 \\
\hline Narrow position, $\%$ & 53.6 & 55.8 \\
\hline
\end{tabular}

${ }^{1} 684$ observation sessions and 4,127 lying events.

${ }^{2} \mathrm{Q} 1=1$ st quartile; $\mathrm{Q} 3=3$ rd quartile.

charge, or increased respiratory rate) had low prevalence and did not differ between systems. However, in both seasons ocular discharge was noticeably more frequent in FWS than in $\mathrm{CH}$, and hampered respiration was considerably higher in FWS in summer.

\section{Comfort Around Resting}

We found a large influence of the housing system on comfort around resting, as shown by all indicators that reflect the welfare criterion comfort around resting (Table 6).

The average time it took cows to lie down varied considerably between systems. Cows in FWS lay down more quickly than in $\mathrm{CH}$ (5.32 in FWS vs. $6 \mathrm{~s}$ in $\mathrm{CH}$ ). Some of the lying events were shorter than $5.20 \mathrm{~s}$ in both systems ( $45.4 \%$ in FWS and $25 \%$ in $\mathrm{CH}$ ), which was considered normal (Welfare Quality, 2009). However, the time for lying down exceeded $6.30 \mathrm{~s}$ in $23.7 \%$ of events in FWS and $42.9 \%$ in $\mathrm{CH}$, indicating serious welfare problems (Welfare Quality, 2009). The percentage of collisions with the environment (housing equipment, other animals) also varied between systems $(7.6 \%$ of events in FWS vs. $35.3 \%$ in $\mathrm{CH}$ ); less than $20 \%$ is considered normal, and greater than $30 \%$ poses a serious welfare problem according to thresholds (Welfare Quality, 2009). The percentage of animals lying partly or completely outside the supposed lying area was $2.9 \%$ in $\mathrm{FWS}$ and $5.7 \%$ in $\mathrm{CH}$; more than $5 \%$ represents a serious welfare problem (Welfare Quality, 2009). We observed seasonal differences, with more cases in winter.

The time needed to lie down (830 events observed) was positively correlated with the percentage of moderate lameness in FWS $\left(\mathrm{r}_{\mathrm{s}}=0.23, P<0.001\right)$ and severe lameness in $\mathrm{CH}\left(\mathrm{r}_{\mathrm{s}}=0.20\right)$. The motivation of cows to lie down is also influenced by the hygiene of the surfaces, and we found correlations $(P<0.05)$ between the time needed to lie down and the percentage of cows with dirty udder and teats, but they were weak $\left(\mathrm{r}_{\mathrm{s}}<0.20\right)$. Longer time for lying down was also highly correlated with the percentage of collisions when lying down $\left(\mathrm{r}_{\mathrm{s}}=\right.$ $0.55, P<0.001)$. The lying process was shorter in herds with grazing, which was valid for both systems.

With respect to rising behavior (849 events observed), mean scores showed easier movement in FWS. Average scores also differed among systems (2.31 in FWS and 2.92 in $\mathrm{CH}$ ). Collisions with the environment also varied between systems (18.4\% in FWS vs. $76.8 \%$ in $\mathrm{CH}$ ).

We explored the lying positions of cows in 684 periods of observation. A total of $43.2 \%(0-100)$ of the cows in FWS were lying during direct observation periods, compared to a total of $44.8 \%(0-100)$ of the cows in $\mathrm{CH}$. We observed all 4 natural lying positions (head back, head up, flat on the side, head on the ground) in the 2 systems. For different cow lying postures, cows in FWS more often adopted different comfortable lying positions than cows in $\mathrm{CH}$. We observed a higher occurrence of long position $(23.1 \%)$ and wide position (38.4\%) events in FWS than in $\mathrm{CH}$, where numbers were 14.5 and $12.9 \%$, respectively.

\section{DISCUSSION}

This study was carried out in 6 countries and constitutes the largest assessment of animal welfare status in FWS currently available. The current study sample can be considered representative of European FWS. The sample included 15\% (the Netherlands) to $100 \%$ (Sweden and Slovenia) of the farms with FWS in each country. The structural characteristics of the $\mathrm{CH}$ herds matched those of the FWS herds, indicating that any differences observed between the 2 groups of herds may have been related to the housing systems. 
It is well known that observational studies are vulnerable to various forms of bias. Some recommendations have been made to minimize such risk (Tuyttens et al., 2014), for instance ensuring that the person collecting the data is unaware of which treatment each subject has received until after the experiment. However, blinding the assessors is not possible in research setups such as the one used in the present study. We claim that the on-farm welfare assessment is both reliable and valid, conditional upon careful experimental design and using a properly trained assessor (exposed to inter-observer reliability in training and intra-observer repeatability testing with video clips and photos belonging to the official training material of Welfare Quality). As well, consensus is growing that protocols assessing animal welfare ought to use ABM whenever possible. The Welfare Quality consortium has promoted ABM; they can be easily observed because they require comparatively little assessor training and usually have high inter- and intra-observer repeatability (Keeling, 2009). Very explicit criteria for each value on a scale make the ratings less dependent on personal experience (Meagher, 2009) and less exposed to judgment (Wemelsfelder, 2007). Nevertheless, we acknowledge that assessing welfare on farms may have limitations that require attention.

We found differences between housing systems, but also huge variation within systems, demonstrating that animal welfare can be promoted regardless of housing system, geographical area, or climatic conditions.

\section{Cow Scoring}

The analysis of ABM associated with cow hygiene and housing systems pointed to important bottlenecks in both housing systems that represent critical issues for cow welfare.

The hygiene of a cow depends on many factors. One is the cleanliness and dryness of the resting areas. Our results indicate that the management of the resting area in both systems can improve, but especially in FWS. The FWS is particularly affected by management skills and requires constant monitoring and addition of new shavings and bedding when needed (Barberg et al., 2007; Black et al., 2013). The hygiene of the body and udder reflect the cleanliness of the lying surface, because those are the parts of the body in contact with the surface when cows are lying down. There are proven associations between udder hygiene and udder health (Schreiner and Ruegg, 2003; Reneau et al., 2005), but the link between hygiene and welfare is complex. For example, a dairy cow may find a bed of warm wet manure or a soaking pond near the water points very comfortable during a hot summer day; however, the cow will be unaware of the elevated risk of mastitis as a result of her action (Cook, 2018). The thermal conditions inside the house might affect hygiene as well. On hot summer days, deep-bedded houses may, therefore, lead to problems if cows have no opportunity to cool off. The preferred floor temperature may vary according to the cow's age or lactation stage. Cows have different preferences under different circumstances.

Having more than 50\% dirty lower hind legs and more than $19 \%$ dirty udders indicates a serious problem in the herd, according to the warning thresholds established by Welfare Quality (2009). The high prevalence of poor hygiene is probably mainly caused by disregarding recommendations for daily cleaning and bedding change in the barns, regardless of housing system. The fact that barn hygiene does not represent a priority for the farmers has been highlighted in other studies (Cook, 2002; Zurbrigg et al., 2005a; Ostojić-Andrić et al., 2011).

The higher prevalence of skin lesions or alterations observed in $\mathrm{CH}$ reflects impaired welfare, because wounds and swellings may be painful, and alterations (including hairless areas) reflect repeated conflicts of the cow with its environment. The direct contribution of some environments to injuries has been very well described (Fraser et al., 2013), and Brenninkmeyer et al. (2016) identified that a specific type of lesion was more related to a specific body area and less likely to appear on different body areas, which is also what we observed in the present study. For example, hair loss over the hocks and knees represents loss due to friction as cows rise and lie down on mats or mattress beds, because the presence of lesions is highly correlated with this type of stall surface compared with the use of well-managed, deep, loose-bedded stalls (Weary and Taszkun, 2000; Cook et al., 2016). Injuries to the hock, on the tarsal joints, are characteristic of extremely exposed areas that are sensitive to pressure when the cow is lying down on a hard or abrasive surface with poor hygiene (Zurbrigg et al., 2005b; Huxley and Whay, 2006; Kielland et al., 2009). Abrasion or ulceration and swelling present an obvious source of pain and infection risk for the cow, and hock injuries have been associated with lameness (Kielland et al., 2009; Potterton et al., 2011). We also observed a correlation between lesions in the tarsus and hindquarters and moderate lameness in $\mathrm{CH}$, and a strong correlation for swelling and severe lameness in both systems.

Lameness prevalence differed between systems. The occurrence of conditions causing lameness is affected by many factors, some of them very well known (herd size, management, facility design, the use of preventive measures for lameness, and cow characteristics; Chapinal et al., 2014; Solano et al., 2015). Most agree that lameness seriously impairs the welfare of cows. However, 
diagnosis of disturbed locomotion should receive more attention, including using sensors to better involve the pain involved in foot diseases and for earlier detection, especially in subclinical cases (Van Nuffel et al., 2015), which by definition are not clearly manifested. The physical environment, including the substrate (e.g., walking surface, resting surface), should be suited to the species and breed, and to the state of the cow, to minimize the risk of injury (Fraser et al., 2013). Thus, the combination of a resting and exercise area and spacious and soft bedding in FWS, in line with the cow's needs, might have had a positive effect in the present study. Another important factor affecting gait is the state of the claws (van der Tol et al., 2004), as well as other environmental factors that change continuously over time (Bran et al., 2019).

The observed higher prevalence of ocular discharge and hampered respiration in FWS has also been described in the United States in compost barns, and have been linked with excessive moisture and dust levels (Janni et al., 2007), the most likely explanation for the same findings in some FWS barns in the present study, but more research is needed on the potential health risks and possible interventions.

\section{Comfort Around Resting}

Our study showed that the housing system affects the welfare of dairy animals. We showed that FWS is especially advantageous when it comes to comfort around resting, because behavioral indicators related to resting suggested that cows were more comfortable in FWS than in CH. This is a very positive effect of FWS, because the resting area is an important factor in the general welfare of dairy cows (OIE, 2019).

Cows should be able to perform the natural movements associated with getting up and lying down without injury (Haley et al., 2001). Lying down and rising up movements are improved when the resting area is correctly designed and has soft and clean bedding. The differences in resting comfort between winter and summer that we observed can be explained by the wetter conditions in winter that could make movements more difficult. Cows' preference to lie down on clean, dry, soft surfaces (Rushen et al., 2007) can be linked to the hygiene of the resting surfaces, and because these are also more stable, they reduce the time needed to lie down. The absence of obstacles that restrict lying down and standing up movements in FWS herds is part of the explanation for the smoother movement and normal sequence of events. The shorter time for getting up and lying down for animals that had opportunities to graze was in agreement with other studies (Krohn and
Munksgaard, 1993; Gustafson and Lund-Magnussen, 1995).

Impaired lying down behavior (longer lying down durations, more collisions during lying down, and more cows lying partly or completely outside the lying area) may result in decreased resting quality in general and can increase the risk for health problems such as body lesions or lameness (Popescu et al., 2013). The correlations we found between comfort around resting and lameness were in agreement with this observation.

The type of housing system influences the lying position that a cow assumes. Uncomfortable stalls reduce the total time lying, because cows cannot adopt certain resting postures (Faull et al., 1996; Sarjokari et al., 2013). In our study, cows were able to show all of the natural lying positions in most of the barns, but the more diverse positions in FWS were similar those adopted in the conditions that pasture provides (Krohn and Munksgaard, 1993). To achieve almost pasture-like conditions in FWS, climatic conditions that affect bedding conditions, choice of optimal bedding material, and considered arrangement of facilities (e.g., water points, concentrate feeders, scrapers) are also important (Lobeck et al., 2011; Mendes Peixoto et al., 2019).

\section{CONCLUSIONS}

Our findings show that FWS is an animal-friendly system for European dairy farmers, particularly for achieving improved cow comfort. The hygiene of cows' coats was deficient in both systems. The large variation in farm prevalence within systems shows ample opportunities to make improvements in both systems. Further investigations are desirable to analyze other influencing factors and identify risk factors.

\section{ACKNOWLEDGMENTS}

We thank the farmers and national researchers from the Freewalk Consortium for their cooperation and support for data collection on the farm. The project receives funding from the European Union's Horizon 2020 Research \& Innovation Programme under grant agreement no. 696231. The authors have not stated any conflicts of interest.

\section{REFERENCES}

Anderson, N. 2008. Cow behaviour to judge free-stall and tie-stall barns. www.omafra.gov.on.ca/english/livestock/dairy/facts/info _cowbehave.htm. Ontario Ministry of Agriculture, Food and Rural Affairs, Guelph, ON, Canada

Barberg, A. E., M. I. Endres, J. A. Salfer, and J. K. Reneau. 2007. Performance and welfare of dairy cows in an alternative housing 
system in Minnesota. J. Dairy Sci. 90:1575-1583. https://doi.org/ 10.3168/jds.S0022-0302(07)71643-0.

Black, R. A., J. L. Taraba, G. B. Day, F. A. Damasceno, and J. M. Bewley. 2013. Compost bedded pack dairy barn management, performance, and producer satisfaction. J. Dairy Sci. 96:8060-8074. https://doi.org/10.3168/jds.2013-6778.

Brambell Committee. 1965. Report of the Technical Committee to Enquire into the Welfare of Animals Kept under Intensive Livestock Husbandry Systems. Her Majesty's Stationery Office, London, UK.

Bran, J. A., J. H. C. Costa, M. A. G. von Keyserlingk, and M. J. Hötzel. 2019. Factors associated with lameness prevalence in lactating cows housed in freestall and compost-bedded pack dairy farms in southern Brazil. Prev. Vet. Med. 172:104773. https://doi.org/10 .1016/j.prevetmed.2019.104773.

Brenninkmeyer, C., S. Dippel, J. Brinkmann, S. March, C. Winckler, and U. Knierim. 2016. Investigating integument alterations in cubicle housed dairy cows: Which types and locations can be combined? Animal 10:342-348. https://doi.org/10.1017/ S1751731115001032.

Chapinal, N., Y. Liang, D. M. Weary, Y. Wang, and M. A. G. von Keyserlingk. 2014. Risk factors for lameness and hock injuries in Holstein herds in China. J. Dairy Sci. 97:4309-4316. https://doi .org/10.3168/jds.2014-8089.

Cook, N. B. 2002. The influence of barn design on dairy cow hygiene, lameness and udder health. Pages 97-103 in Proc. 35th Annu. Conv. Am. Assoc. Bovine Practitioners, Madison, WI. Am. Assoc. Bovine Practitioners, Ashland, $\mathrm{OH}$

Cook, N. B. 2018. Assessment of Cattle Welfare: Common AnimalBased Measures. Advances in Cattle Welfare. Elsevier Ltd., New York.

Cook, N. B., J. P. Hess, M. R. Foy, T. B. Bennett, and R. L. Brotzman. 2016. Management characteristics, lameness, and body injuries of dairy cattle housed in high-performance dairy herds in Wisconsin. J. Dairy Sci. 99:5879-5891. https://doi.org/10.3168/jds.2016 $-10956$.

Drissler, M., M. Gaworski, C. B. Tucker, and D. M. Weary. 2005. Freestall maintenance: Effects on lying behavior of dairy cattle. J. Dairy Sci. 88:2381-2387. https://doi.org/10.3168/jds.S0022 -0302(05)72916-7.

EFSA. 2009. Scientific report on the effects of farming systems on dairy cow welfare and disease. Report of the Panel on Animal Health and Welfare. EFSA J. 1143:1-38.

EFSA. 2012. Scientific opinion on the welfare of cattle kept for beef production and the welfare in intensive calf farming systems. EFSA J. 10:2669. https://doi.org/10.2903/j.efsa.2012.2669.

Endres, M. I., and A. E. Barberg. 2007. Behavior of dairy cows in an alternative bedded-pack housing system. J. Dairy Sci. 90:41924200. https://doi.org/10.3168/jds.2006-751.

Eurobarometer. 2016. Special Eurobarometer 442 on Attitudes of Europeans towards Animal Welfare. Accessed Jan. 22, 2020. http:/ /data.europa.eu/euodp/en/data/dataset/S2096_84_4_442_ENG.

European Union. 2017. Overview Report Welfare of Cattle on Dairy Farms. DG Health and Food Safety. https://doi.org/10.2875/ 815860.

Faull, W. B., J. W. Hughes, M. J. Clarkson, D. Y. Downham, F. J. Manson, J. B. Merritt, R. D. Murray, W. B. Russell, J. E. Sutherst, and W. R. Ward. 1996. Epidemiology of lameness in dairy cattle: The influence of cubicles and indoor and outdoor walking surfaces. Vet. Rec. 139:130-136. https://doi.org/10.1136/ vr.139.6.130.

Fraser, D., I. J. Duncan, S. A. Edwards, T. Grandin, N. G. Gregory, V. Guyonnet, P. H. Hemsworth, S. M. Huertas, J. M. Huzzey, D. J. Mellor, J. A. Mench, M. Špinka, and H. R. Whay. 2013. General principles for the welfare of animals in production systems: The underlying science and its application. Vet. J. 198:19-27. https:// doi.org/10.1016/j.tvjl.2013.06.028.

Fregonesi, J. A., M. A. G. von Keyserlingk, and D. M. Weary. 2009. Cow preference and usage of free stalls compared with an open pack area. J. Dairy Sci. 92:5497-5502. https://doi.org/10.3168/ jds.2009-2331.
Galama, P. J. 2011. Prospects for Bedded Pack Barns for Dairy Cattle. Wageningen UR Livestock Research, Wageningen, the Netherlands.

Grandin, T. 2018. Welfare problems in cattle, pigs, and sheep that persist even though scientific research clearly shows how to prevent them. Animals (Basel) 8:124. https://doi.org/10.3390/ani8070124.

Gustafson, G. M., and E. Lund-Magnussen. 1995. Effect of daily exercise on the getting up and lying down behavior of tied dairy cows. Prev. Vet. Med. 25:27-36. https://doi.org/10.1016/0167 $-5877(95) 00496-3$.

Haley, D. B., A. M. de Passille, and J. Rushen. 2001. Assessing cow comfort: Effects of two floor types and two tie stall designs on the behaviour of lactating dairy cows. Appl. Anim. Behav. Sci. 71:105-117.

Hötzel, M. J. 2014. Improving farm animal welfare: Is evolution or revolution needed in production systems? Pages 67-84 in Dilemmas in Animal Welfare. M. C. Appleby, D. M. Weary, and P. Sandøe, ed. CABI, Wallingford, UK.

Huxley, J., and H. R. Whay. 2006. Welfare: Cow-based assessments Part 2: Rising restrictions and injuries associated with the lying surface. Livestock 11:33-38. https://doi.org/10.1111/j.2044-3870 2006.tb00035.x.

Janni, K. A., M. I. Endres, J. K. Reneau, and W. W. Schoper. 2007. Compost dairy barn layout and management recommendations. Appl. Eng. Agric. 23:97-102. https://doi.org/10.13031/2013 .22333 .

Keeling, L. 2009. An Overview of the Development of the Welfare Quality Assessment Systems. Welfare Quality Reports No. 12. Cardiff University, Cardiff, UK.

Kielland, C., L. E. Ruud, A. J. Zanella, and O. Østerås. 2009. Prevalence and risk factors for skin lesions on legs of dairy cattle housed in freestalls in Norway. J. Dairy Sci. 92:5487-5496. https://doi .org/10.3168/jds.2009-2293.

Krohn, C. C., and L. Munksgaard. 1993. Behavior of dairy cows kept in extensive (loose housing/pasture) or intensive (tie stall) environments II. Lying and lying down behavior. Appl. Anim. Behav. Sci. 37:1-16. https://doi.org/10.1016/0168-1591(93)90066-X.

Krug, C., M. J. Haskell, T. Nunes, and G. Stilwell. 2015. Creating a model to detect dairy cattle farms with poor welfare using a national database. Prev. Vet. Med. 122:280-286. https://doi.org/10 .1016/j.prevetmed.2015.10.014.

Leach, K. A., and H. R. Whay. 2009. The Welfare Quality Lameness Control Programme for Dairy Cattle: Resources to Help Farmers and Advisors Tackle Lameness Problems in Dairy Herds. Welfare Quality Reports no. 14. Accessed Jan. 22, 2020. http://www .welfarequality.net/media/1122/wqr14.pdf.

Leso, L., M. Uberti, W. Morshed, and M. Barbari. 2013. A survey on Italian compost dairy barns. J. Agric. Eng. XLIV(Suppl. 2):e40. https://doi.org/10.4081/jae.2013.282.

Lobeck, K. M., M. I. Endres, E. M. Shane, S. M. Godden, and J. Fetrow. 2011. Animal welfare in cross-ventilated, compost-bedded pack, and naturally ventilated dairy barns in the upper Midwest. J. Dairy Sci. 94:5469-5479. https://doi.org/10.3168/jds.2011-4363.

Meagher, R. K. 2009. Observer ratings: Validity and value as a tool for animal welfare research. Appl. Anim. Behav. Sci. 119:1-14. https: //doi.org/10.1016/j.applanim.2009.02.026.

Mendes Peixoto, M. S., J. A. D. Barbosa Filho, N. A. Farias Machado, V. De Sena Sales Viana, and J. F. Martins Costa. 2019. Thermoregulatory behavior of dairy cows submitted to bedding temperature variations in Compost barn systems. Biol. Rhythm Res. https: //doi.org/10.1080/09291016.2019.1616904.

Munksgaard, L., M. B. Jensen, L. J. Pedersen, S. W. Hansen, and L. Matthews. 2005. Quantifying behavioural priorities: Effects of time constraints on behaviour of dairy cows, Bos taurus. Appl. Anim. Behav. Sci. 92:3-14. https://doi.org/10.1016/j.applanim 2004.11.005.

Ofner-Schröck, E., M. Zähner, G. Huber, K. Guldimann, T. Guggenberger, and J. Gasteiner. 2015. Compost barns for dairy cows - aspects of animal welfare. Open J. Anim. Sci. 5:124-131. https://doi .org/10.4236/ojas.2015.52015. 
OIE. 2019. Animal Welfare and Dairy Cattle Production Systems in Terrestrial Animal Health Code. 28th ed. OIE, Paris, France.

Ostojić-Andrić, D., S. Hristov, Z. Novaković, V. Pantelić, M. M. Petrović, Z. Zlatanović, and D. Nikšić. 2011. Dairy cows welfare quality in loose vs tie housing system. Biotechnol. Anim. Husb. 27:975-984. https://doi.org/10.2298/BAH1103975O.

Popescu, S., C. Borda, E. A. Diugan, M. Spinu, I. S. Groza, and C. D. Sandru. 2013. Dairy cows welfare quality in tie-stall housing system with or without access to exercise. Acta Vet. Scand. 55:43. https://doi.org/10.1186/1751-0147-55-43.

Potterton, S. L., M. J. Green, J. Harris, K. M. Millar, H. R. Whay, and J. N. Huxley. 2011. Risk factors associated with hair loss, ulceration, and swelling at the hock in freestall-housed UK dairy herds. J. Dairy Sci. 94:2952-2963. https://doi.org/10.3168/jds .2010-4084.

Reneau, J. K., A. J. Seykora, B. J. Heins, M. I. Endres, R. J. Farnsworth, and R. F. Bey. 2005. Association between hygiene scores and somatic cell scores in dairy cattle. J. Am. Vet. Med. Assoc. 227:1297-1301. https://doi.org/10.2460/javma.2005.227.1297.

Rushen, J., D. Haley, and A. M. De Passillé. 2007. Effect of softer flooring in tie stalls on resting behavior and leg injuries of lactating cows. J. Dairy Sci. 90:3647-3651. https://doi.org/10.3168/jds .2006-463.

Rutherford, K. M. D., F. M. Langford, M. C. Jack, L. Sherwood, A B. Lawrence, and M. J. Haskell. 2009. Lameness prevalence and risk factors in organic and non-organic dairy herds in the United Kingdom. Vet. J. 180:95-105. https://doi.org/10.1016/j.tvjl.2008 .03 .015

Sarjokari, K., K. O. Kaustell, T. Hurme, T. Kivinen, O. A. T. Peltoniemi, H. Saloniemi, and P. J. Rajala-Schultz. 2013. Prevalence and risk factors for lameness in insulated free stall barns in Finland. Livest. Sci. 156:44-52. https://doi.org/10.1016/j.livsci.2013.06 .010 .

Schreiner, D. A., and P. L. Ruegg. 2003. Relationship between udder and leg hygiene scores and subclinical mastitis. J. Dairy Sci. 86:3460-3465. https://doi.org/10.3168/jds.S0022-0302(03)73950 -2 .

Solano, L., H. W. Barkema, E. A. Pajor, S. Mason, S. J. LeBlanc, J. C. Zaffino Heyerhoff, C. G. R. Nash, D. B. Haley, E. Vasseur, D. Pellerin, J. Rushen, A. M. de Passillé, and K. Orsel. 2015. Prevalence of lameness and associated risk factors in Canadian HolsteinFriesian cows housed in freestall barns. J. Dairy Sci. 98:6978-6991. https://doi.org/10.3168/jds.2015-9652.

Somers, J. G. C. J., K. Frankena, E. N. Noordhuizen-Stassen, and J. H. M. Metz. 2003. Prevalence of claw disorders in Dutch dairy cows exposed to several floor systems. J. Dairy Sci. 86:2082-2093. https://doi.org/10.3168/jds.S0022-0302(03)73797-7.

Tillie, M. 1986. European free stall housing: Historical development and present systems. Pages 5-19 in Proc. Dairy Free Stall Sympo- sium. Northeast Regional Agricultural Engineering Service, Harrisburg, PA.

Toussaint-Raven, E. 2003. Cattle Foot Care and Trimming. Crowood Press Ltd., Wiltshire, UK.

Tucker, C. B., and D. M. Weary. 2001. Stall design: Enhancing cow comfort. Adv. Dairy Tech. 13:155-168.

Tucker, C. B., D. M. Weary, M. A. G. von Keyserlingk, and K. A. Beauchemin. 2009. Cow comfort in tie-stalls: Increased depth of shavings or straw bedding increases lying time. J. Dairy Sci. 92:2684-2690. https://doi.org/10.3168/jds.2008-1926.

Tuyttens, F. A. M., S. de Graaf, J. L. T. Heerkens, L. Jacobs, E. Nalon, S. Ott, L. Stadig, E. Van Laer, and B. Ampe. 2014. Observer bias in animal behaviour research: Can we believe what we score, if we score what we believe? Anim. Behav. 90:273-280. https://doi .org/10.1016/j.anbehav.2014.02.007.

van der Tol, P. P. J., S. S. van der Beek, J. H. M. Metz, E. N. Noordhuizen-Stassen, W. Back, C. R. Braam, and W. A. Weijs. 2004 The effect of preventive trimming on weight bearing and force balance on the claws of dairy cattle. J. Dairy Sci. 87:1732-1738. https: //doi.org/10.3168/jds.S0022-0302(04)73327-5.

Van Nuffel, A., I. Zwertvaegher, S. Van Weyenberg, M. Pastell, V. M. Thorup, C. Bahr, B. Sonck, and W. Saeys. 2015. Lameness detection in dairy cows: Part 2. Use of sensors to automatically register changes in locomotion or behavior. Animals (Basel) 5:861-885 https://doi.org/10.3390/ani5030388.

Veissier, I., J. Capdeville, and E. Delval. 2004. Cubicle housing systems for cattle: Comfort of dairy cows depends on cubicle adjustment. J. Anim. Sci. 82:3321-3337. https://doi.org/10.2527/2004 $.82113321 \mathrm{x}$.

Weary, D. M., and I. Taszkun. 2000. Hock lesions and free-stall design. J. Dairy Sci. 83:697-702.

Webster, A. J. F. 2001. Effects of housing and two forage diets on the development of claw horn lesions in dairy cows at first calving and in first lactation. Vet. J. 162:56-65. https://doi.org/10.1053/tvjl .2001.0569.

Welfare Quality. 2009. Welfare Quality Assessment Protocol for Cattle. Welfare Quality Consortium, Lelystad, the Netherlands.

Wemelsfelder, F. 2007. How animals communicate quality of life: The qualitative assessment of behaviour. https:// animalstudiesrepository.org/ cgi/viewcontent.cgi?article=1099\& context=acwp_asie.

Zurbrigg, K., D. Kelton, N. Anderson, and S. Millman. 2005a. Tie-stall design and its relationship to lameness, injury, and cleanliness on 317 Ontario dairy farms. J. Dairy Sci. 88:3201-3210. https://doi .org/10.3168/jds.S0022-0302(05)73003-4.

Zurbrigg, K., D. Kelton, N. Anderson, and S. Millman. 2005b. Stall dimensions and the prevalence of lameness, injury, and cleanliness on 317 tie-stall dairy farms in Ontario. Can. Vet. J. 46:902-909. 